Scientific Journal of Hamadan Nursing \& Midwifery Faculty - ISSN 2008-2819

\title{
Based on Acceptance and Commitment Therapy on Depression, Self-Esteem and Body Image Concerns, After the First Birth, Women in Kashan City
}

\author{
Bahareh Rasooli Ali Abadi ${ }^{1}$, Mehrdad Kalantari ${ }^{2 *}$ \\ 1. MSc in Clinical Psychology, Islamic Azad University, Khorasgan Branch, Isfahan, Iran \\ 2. PhD in Clinical Psychology, Assistant Professor, Department of Psychology, Faculty of Psychology and Educa- \\ tional Sciences, University of Isfahan, Isfahan, Iran
}

Article Info $\quad$ Abstract

Received: $\quad$ 2017/06/16

Accepted: $\quad 2017 / 08 / 29$

Published Online 2018/03/16

DOI: $10.30699 /$ sjhnmf.26.2.103

Original Article

Use your device to scan and read the article online

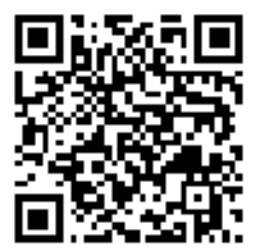

Introduction: The aim of this study was to determine the effectiveness of acceptance and commitment therapy on depression, self-esteem and body image concerns, after the first delivery in women in Kashan.

Methods: This was a quasi-experimental study with a pre-test and the post-test and a control group. For this purpose from all women who gave birthfot the first timein in city of Kashan, 87 patients were screened in 2016 using convenience sampling. Of them, 30 were selected, and randomly placed in two groups: experimental and control. To do the pre-test and the post-test and collect information Edinburgh Postnatal Depression Scale, Self Esteem Inventory and body image concern inventory questionnaires were used. The treatment plan of acceptance and commitment was conducted during 1 month with 8 sessions of 90 minutes and after the implementation of the post-test data was analyzed using analysis of covariance with repeated measures.

Results: The present study shows that there is a significant difference between the subjects of the experimental and control groups in terms of one of the dependent variables (depression, self-esteem and physical deformity) $(\mathrm{F}=19.19, P<0.01)$. The results showed that there is a significant difference between the experimental group and the control group in terms of depression $(\mathrm{F}=95.85, P<0.0001)$, self-esteem $(\mathrm{F}=91.65, P<0.0001)$, and physical deformity $(\mathrm{F}=117.04, P<0.0001)$.

Conclusion: According to the results obtained we can conclude that acceptance and commitment therapy can reduce depression and concerns about body image and increase self-esteem of women after the first delivery.

Keywords: Acceptance and Commitment Therapy, Postpartum Depression, Self-Esteem, Body Image Concerns

Mehrdad Kalantari, PhD in Clinical Psychology, Assistant Professor, Department of Psychology, Faculty of Psychology and Educational Sciences, University of Isfahan, Isfahan, Iran E-mail: kalantari m@yahoo.com, Tel: 09360242218

Corresponding Information

Copyright $($ C 2018, Sci J Hamadan Nurs Midwifery Fac. This is an open-access article distributed under the terms of the Creative Commons Attribution-noncommercial 4.0 International License which permits copy and redistribute the material just in noncommercial usages, provided the original work is properly cited.

How to Cite This Article:

Rasooli Ali Abadi B, Kalantari M. Based on Acceptance and Commitment Therapy on Depression, Self-Esteem and Body Image Concerns, After the First Birth, Women in Kashan City. Sci J Hamadan Nurs Midwifery Fac. 2018; 26 (2): 103- 112 


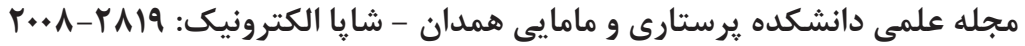

مقاله يثوهشى

اثربخشى درمان مبتنى بر پذيرش و تعهد بر افسردَى، عزتنفس و نگَرانى تصوير بدنى، بعد از اولين زايمان زنان شهرستان كاشان

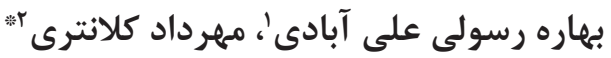

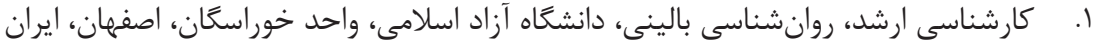

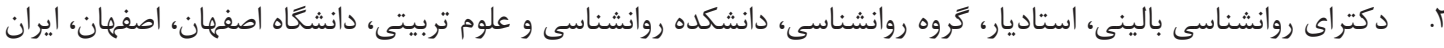

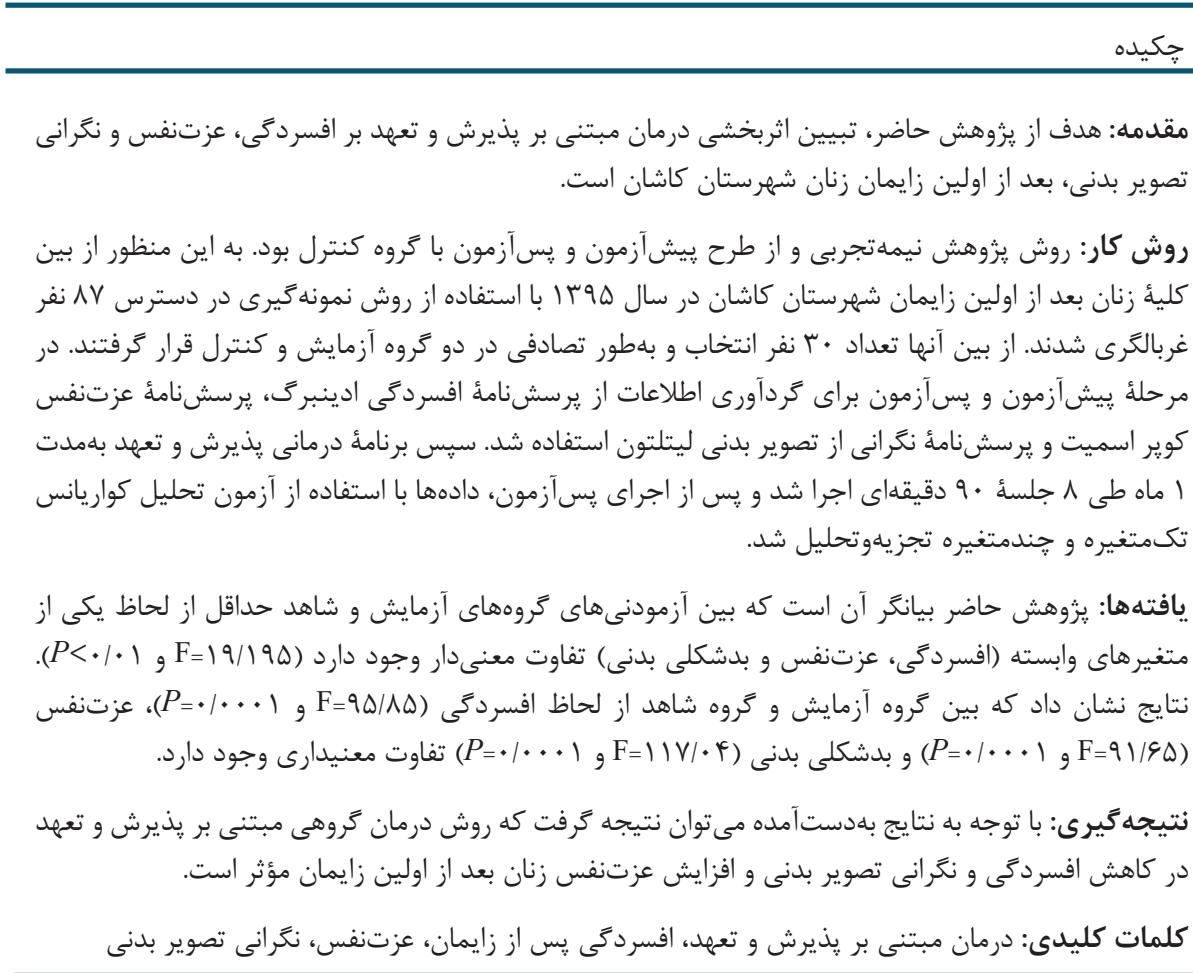

اطلاعات مقاله

\section{تاريخ وصول: : ت \\ تاريخ يذيرش:

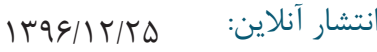 \\ نويسندهُمسئول: \\ مهرداد كلانترى \\ ادكتراى روانشناسى بالينى،

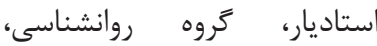

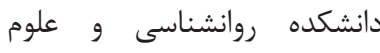 تربيتى، دانشعاه اصفهان، اصفهان، \\ ايران \\ تلفن: \\ . 9TG. TFTTIN \\ يست الكترونيك:}

kalantari_m@yahoo.com

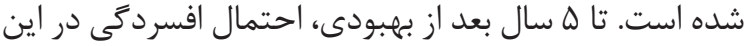

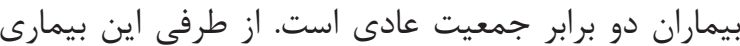

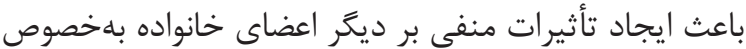

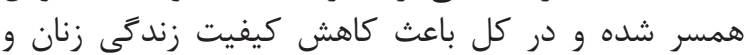

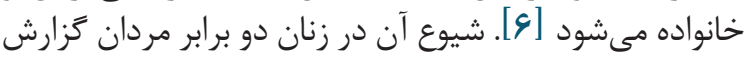

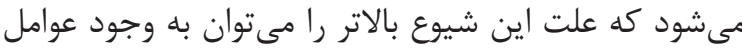

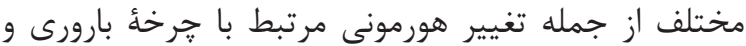

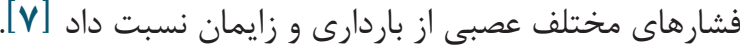

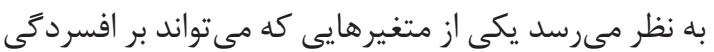

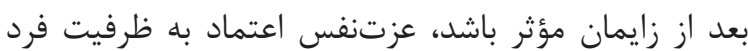

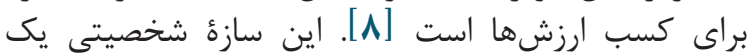

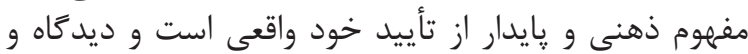

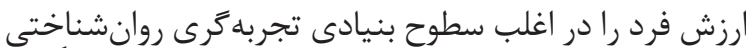

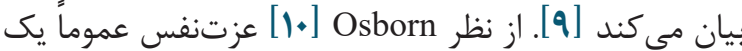

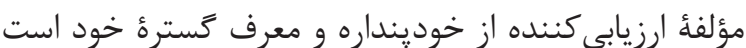

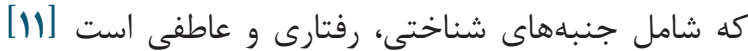

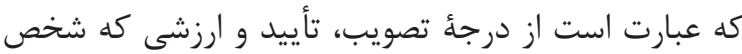

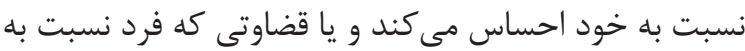
ارزش خود دارد [rا]]. از تفاوت خود احس ادراكشده يا خودينداره

دوره צץ شماره Y - خرداد و تير Vqr

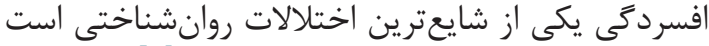

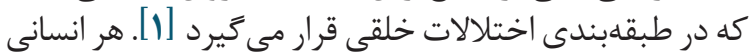

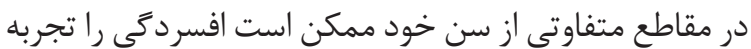

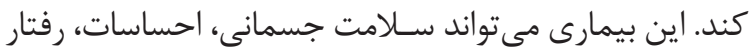

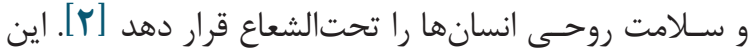

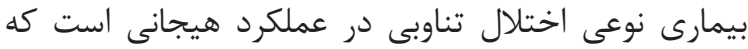

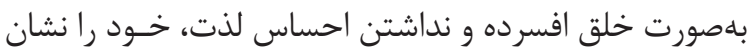

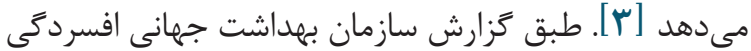

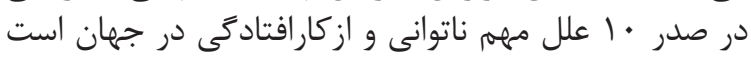

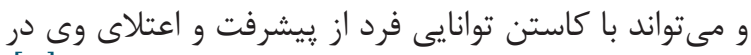

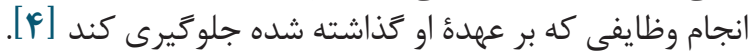

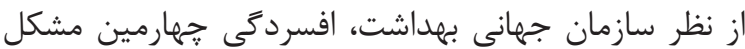

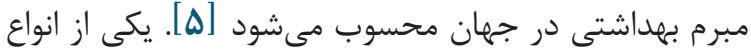

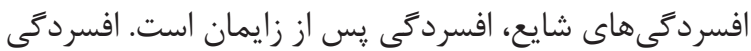

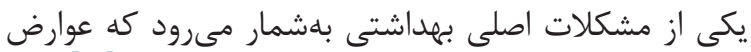

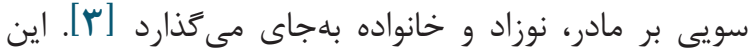

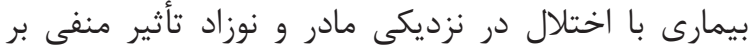

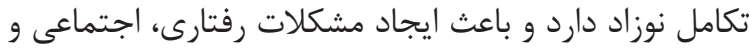

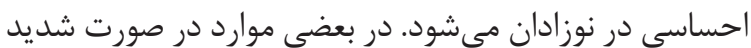

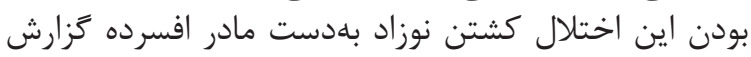
مجله علمى دانشكده يرستارى و مامايى همدان 
براى سالم بودن بايد از آنها خلاص شد كه اين باعث منازعأِ

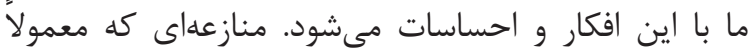

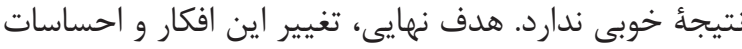

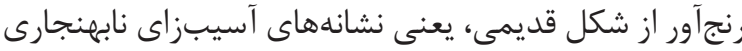

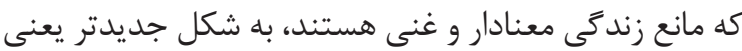

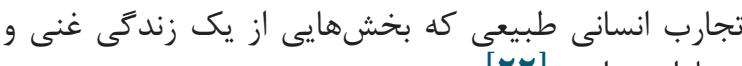

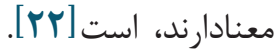

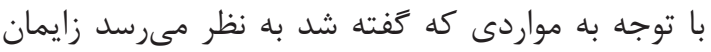

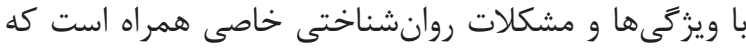

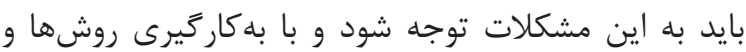

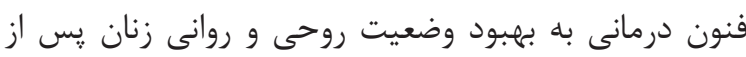

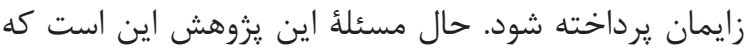

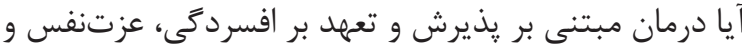

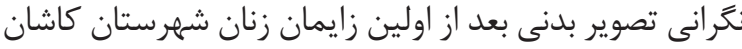

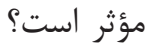

\section{روش كار}

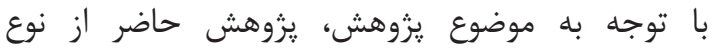

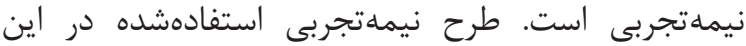

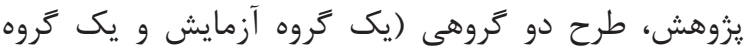

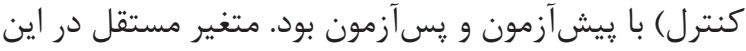

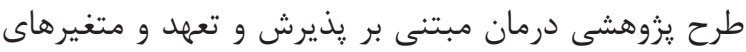

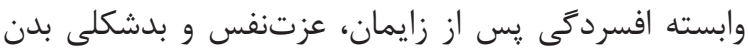

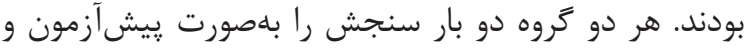

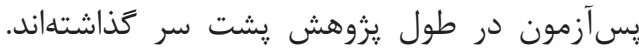

جامعأ آمارى اين يزوهش شامل كليهٔ زنان بعد از اولين

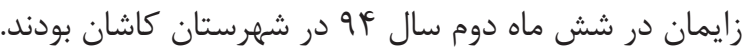

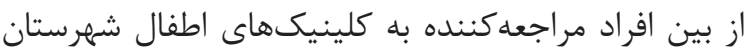

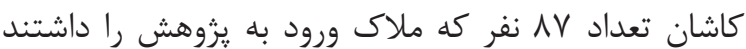

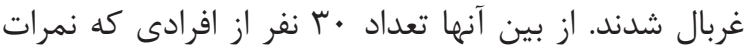

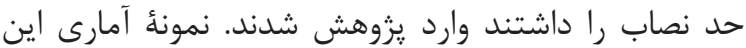

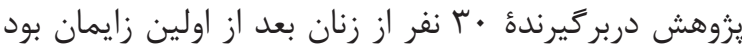

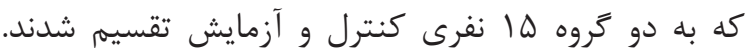

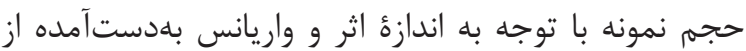

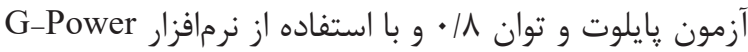

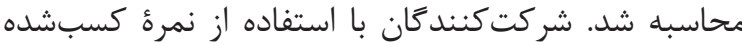

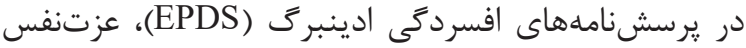

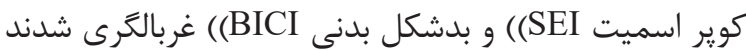

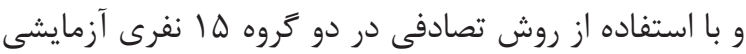

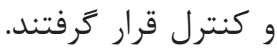

قابل ذكر است كه با توجه به ريزش افراد شركت كننده در درو

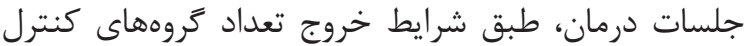

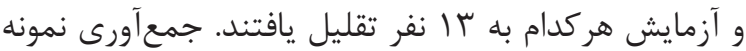

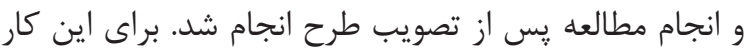

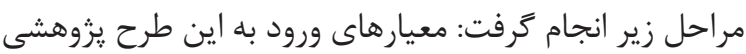

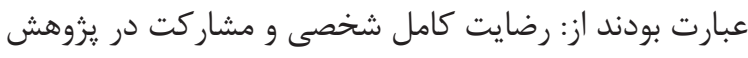

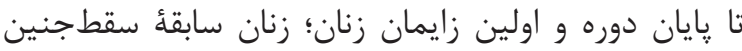

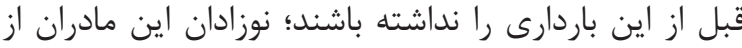

(يك نظر عينى از خود) و خود ايدهآل (آنجه شخص با با ارزش

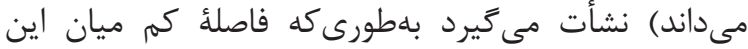

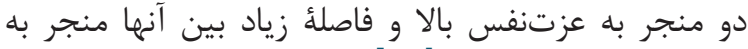

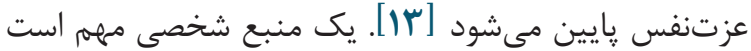

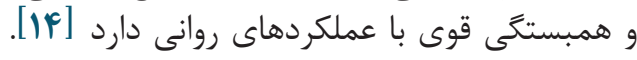

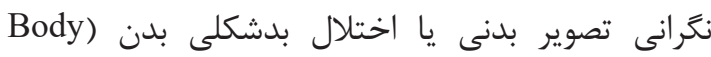

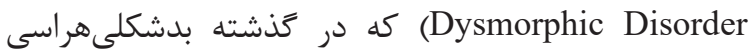

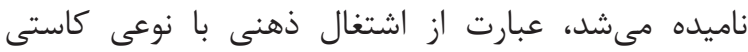

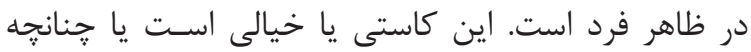

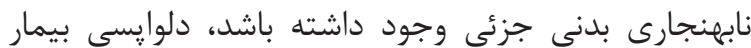

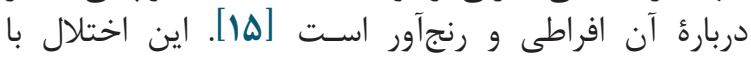

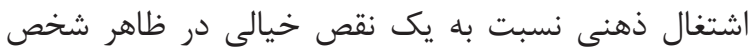

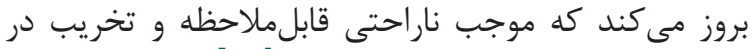

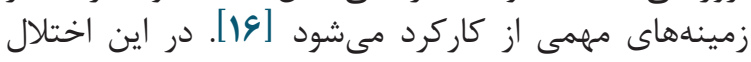

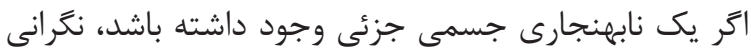

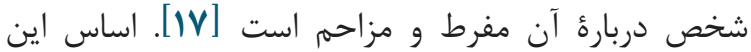

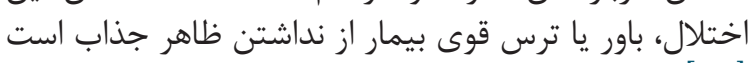

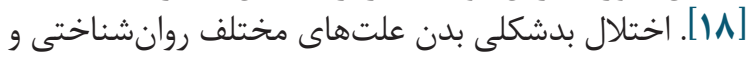

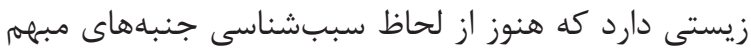

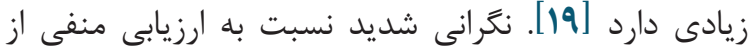

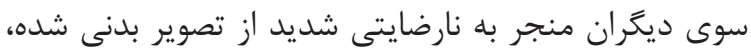

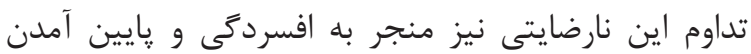

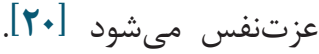

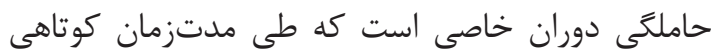

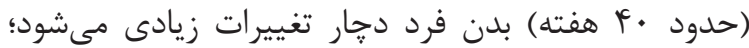

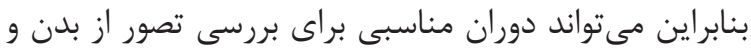

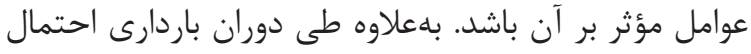

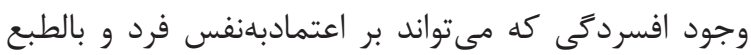

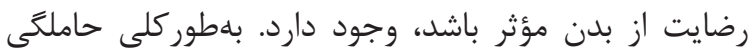

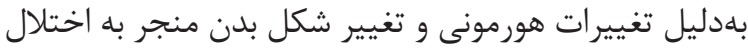

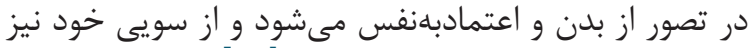

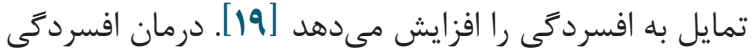

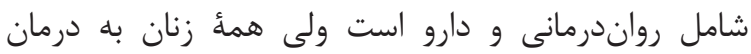

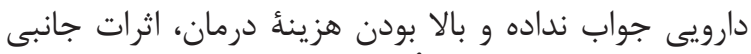

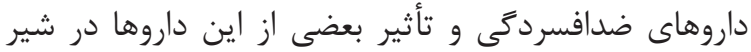

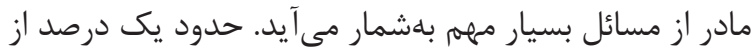

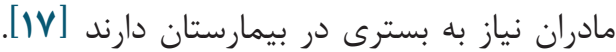

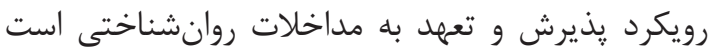

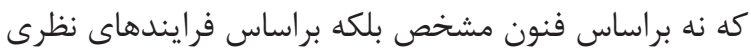

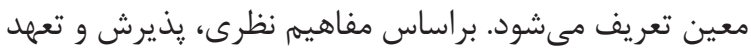

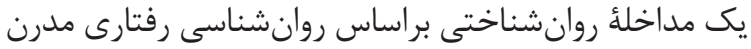

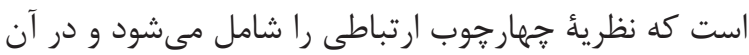

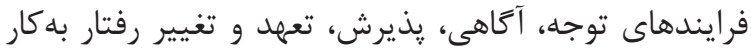

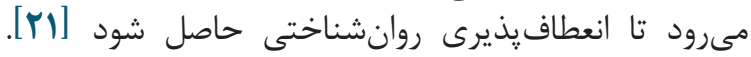

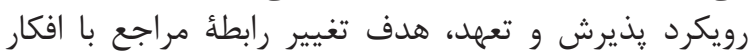

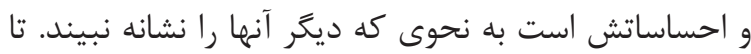

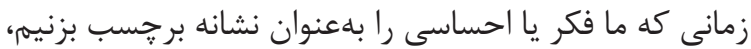

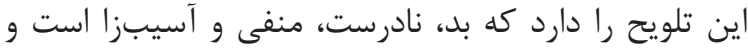




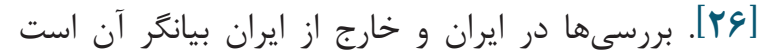

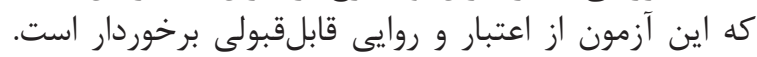

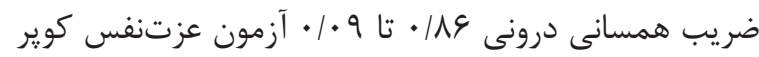

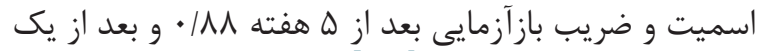

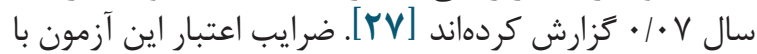

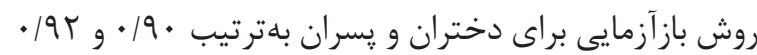

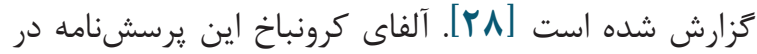

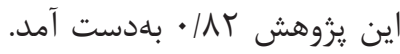

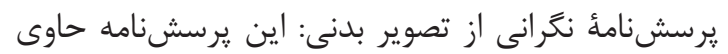

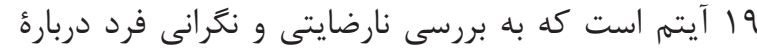

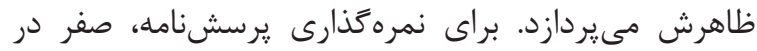

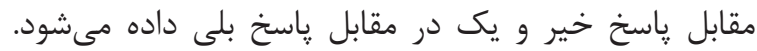

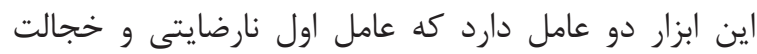

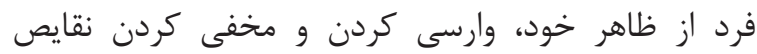

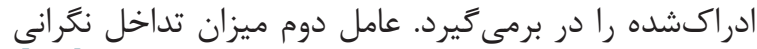

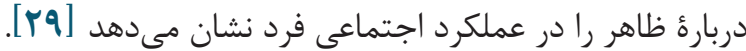

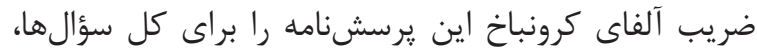

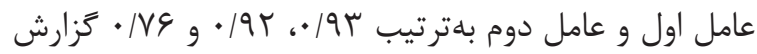

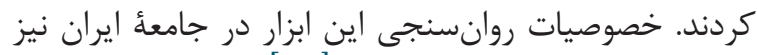

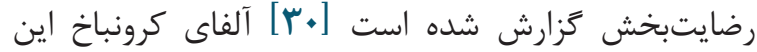

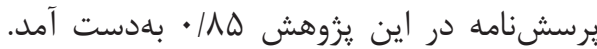

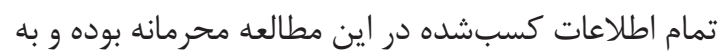

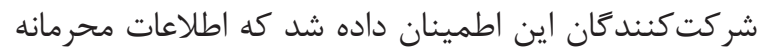

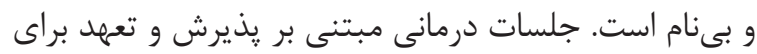

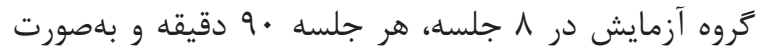

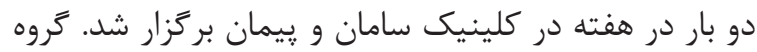

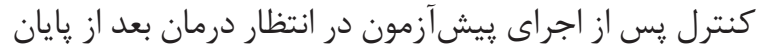

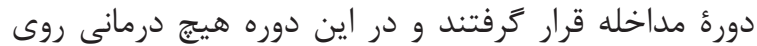

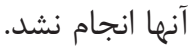

سرفصلهاى جلسات درمانى مبتنى بر يذيرش و تعرديد

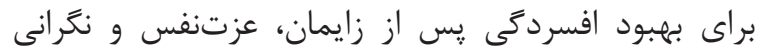

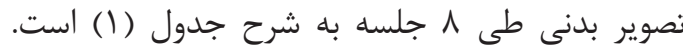

نظر جسمى و ذهنى سالم باشند؛ سواد مادران بايد حداقل

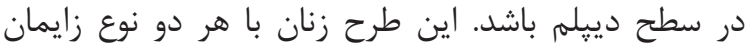

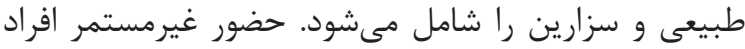

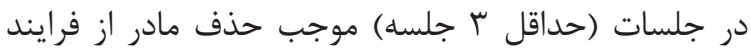

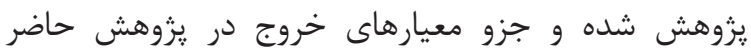

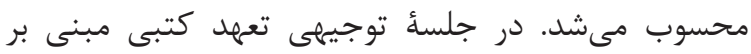

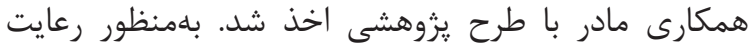

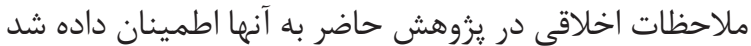

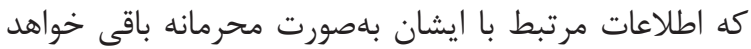

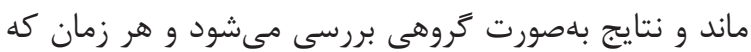

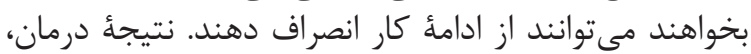

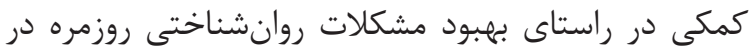

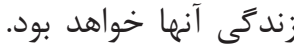

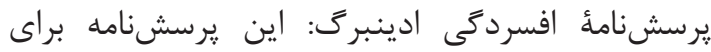

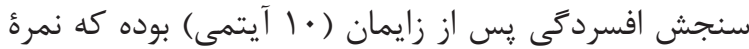

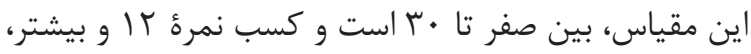

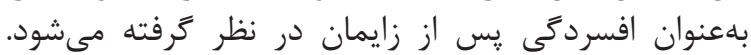

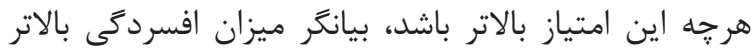

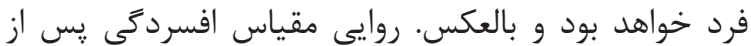

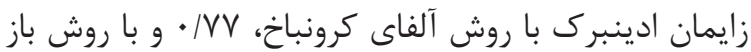

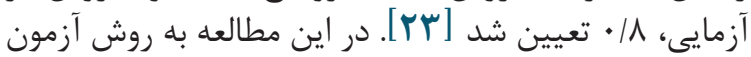

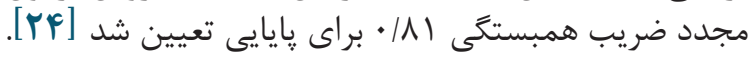

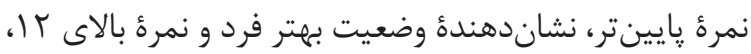

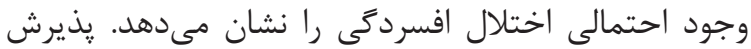

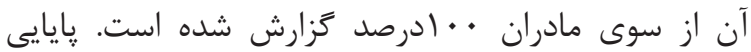

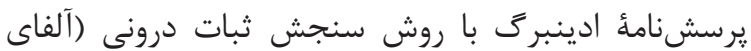

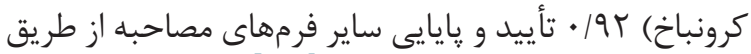

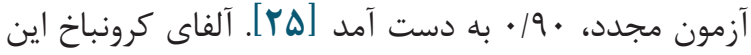

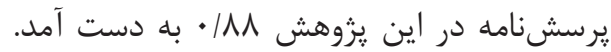

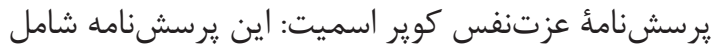

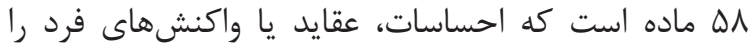

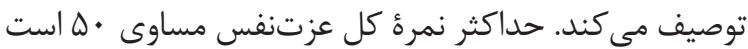

جدول ا. خلاصٔ جلسات درمان مبتنى بر يذيرش و تعهد

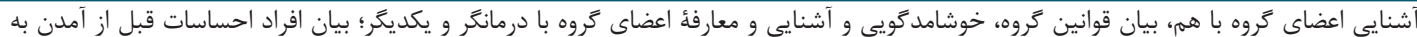

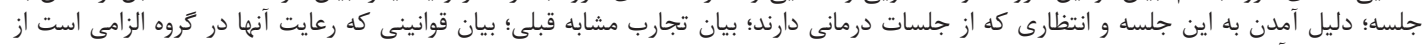

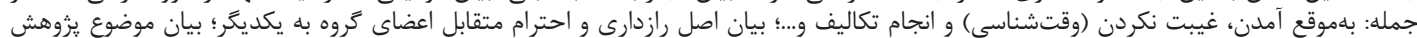

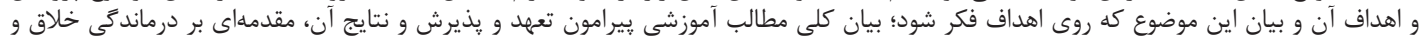
استفاده از استعاره و دادن تكليف

سنجش عملكرد، مرور واكنشها به جلسؤ قبل، مرور تكاليف، ادامٔ درماندگى خلاق، استفاده از استعاره و دادن تكليف

سنجش عملكرد، مرور واكنشها به جلسئ قبل، مرور تكاليف، بيان كنترل بهعنوان مسئله، استفاده از استعاره و دادن تكليف

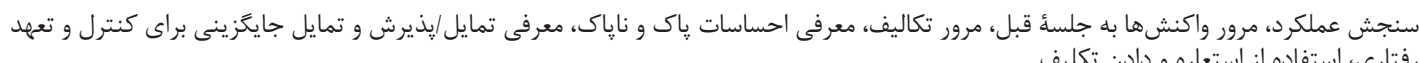

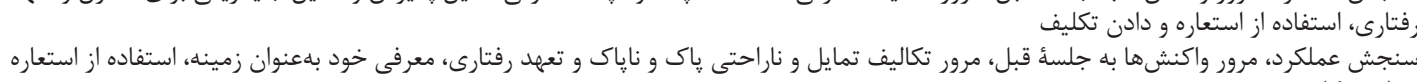
و وادن تكليف

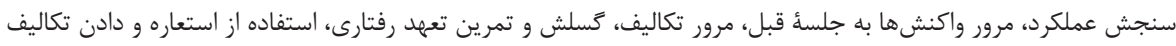

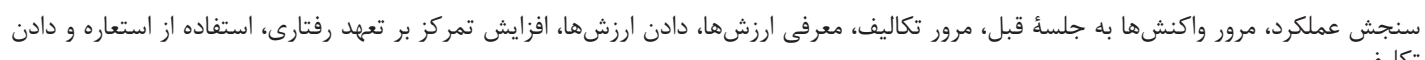

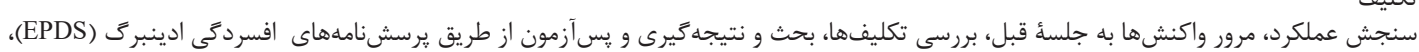

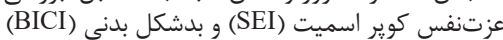

جلسئ اول

جلسئ دوم

جلسئ سوم جلسهٔ جهارم جلسة هنجم جلسئ ششم جلسئ هفتم جلسئ هشتم 
جدول r. فراوانى و درصد فراوانى مشخصات فردى شركت كنندكان

\begin{tabular}{|c|c|c|}
\hline \multicolumn{2}{|c|}{ فراوانى } & \multirow[t]{2}{*}{ متغير هاى جمعيتشناختى } \\
\hline درصد & ت تعداد & \\
\hline & & سن (سال) \\
\hline$\uparrow \& / 9$ & If & $>r$. \\
\hline \multirow[t]{2}{*}{$\Delta F / F$} & 19 & $r \cdot-f$. \\
\hline & & وضعيت تأهل \\
\hline $9 \pi / r$ & $r \Lambda$ & متأهل \\
\hline \multirow[t]{2}{*}{$V / V$} & r & مطلقه \\
\hline & & ميزان تحصيلات \\
\hline$\kappa r / r$ & ז & دييلم \\
\hline \multirow[t]{2}{*}{$\Delta S / V$} & iv & فوق ديبلم \\
\hline & & نوع زايمان \\
\hline v. & rI & طبيعى \\
\hline$r$. & 9 & سزارين \\
\hline
\end{tabular}

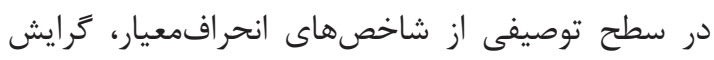

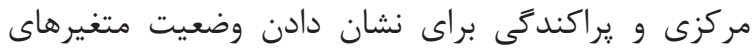

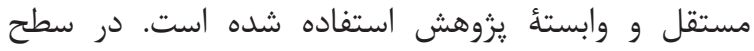

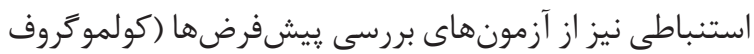

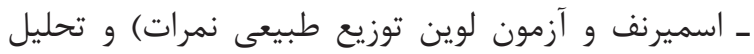

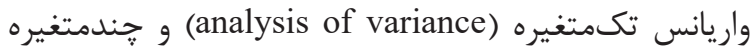
(multivariate analysis of variance) كرونباخ استفاده شده است. كلئ تحليل هاى آمارى با استفاده از بستُ آمارى براى علوماجتماعى (Statistical Package for Social Sciences

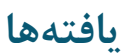

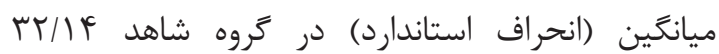

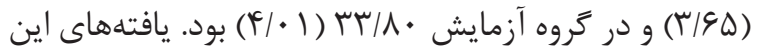

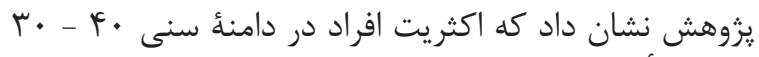

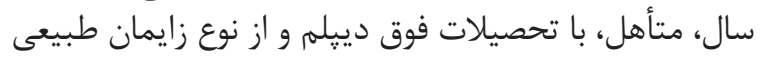

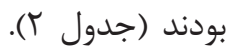

جدول r. شاخصهاى توصيفى افسردحى در آزمودنىهاى تروههاى آزمايش و شاهد در مراحل يِيش آزمون و يس آزمون

\begin{tabular}{|c|c|c|c|c|c|c|c|}
\hline تعداد & حداكثر نمره & حداقل نمره & انحراف معيار & ميانگين & شاخص آمارى كروه & مر حله & متغير \\
\hline ir & 11 & 11 & $1 / 90$ & $\mid F / A F$ & آزمايش & \multirow{2}{*}{ يِيشآزمون } & \multirow{4}{*}{$\bar{g}$} \\
\hline ir & $r$. & 11 & $r|9|$ & DQR/T & شاهد & & \\
\hline ir & Ir & 4 & $r / l F$ & $9 / \Delta r$ & آزمايش & \multirow{2}{*}{ يسآزمون } & \\
\hline Ir & 11 & Ir & $r /$. & $1 \Delta / r T$ & شاهد & & \\
\hline ir & 10 & v & $r / F A$ & 11 & آزمايش & \multirow{2}{*}{ يِيش آزمون } & \multirow{4}{*}{$\begin{array}{l}\text { y } \\
: 3 \\
: 32\end{array}$} \\
\hline ir & 14 & v & T/QT & $1 \cdot 199$ & شاهد & & \\
\hline 11 & Tr & 9 & $\Gamma / \Delta$. & $\mid g / 49$ & آزمايش & \multirow{2}{*}{ يسآزمون } & \\
\hline $1 r$ & 10 & v & T/T & $1 \cdot / A F$ & شاهد & & \\
\hline ir & EV & $r F$ & F/Tr & $f \cdot 199$ & آزمايش & \multirow{2}{*}{ يِيشآزمون } & \multirow{2}{*}{$\begin{array}{l}3 \\
3 \\
y\end{array}$} \\
\hline ir & ro & $\psi_{1}$ & س & $F I / T \Lambda$ & 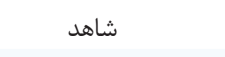 & & \\
\hline $1 r$ & k & $r \Lambda$ & $F / F$ & $r \mu / \cdot V$ & آزمايش & \multirow{2}{*}{ يس آزمون } & \multirow{2}{*}{3} \\
\hline $1 r$ & is & re & $r / 99$ & $f \mid / k \varepsilon$ & شاهد & & \\
\hline
\end{tabular}

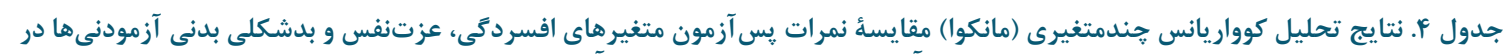

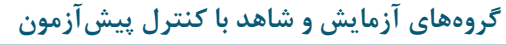

\begin{tabular}{|c|c|c|c|c|c|c|}
\hline مجذور اتا & سطح معنى دارى P & $\mathbf{F}$ & خطا Df & Df فرضيه Df & مقدار & نام آزمون \\
\hline . $/ V T F$ & $\cdot / \cdots)$ & $19 / 190$ & rT & r & - MTY & آزمون اثر ييلايى \\
\hline . MTY & $\cdot \cdots 1$ & $19 / 190$ & tr & r & $\cdot / r V G$ & آزمون لامبداى ويلكز \\
\hline - IVTY & $\cdot 1 \cdot \cdots 1$ & $19 / 190$ & tr & r & $r|9|$ & آزمون اثر هتلينَ \\
\hline . MYYF &.$/ \cdots 1$ & $19 / 190$ & rt & r & $r|9|$ & آزمون بزركتر ين ريشه روى \\
\hline
\end{tabular}

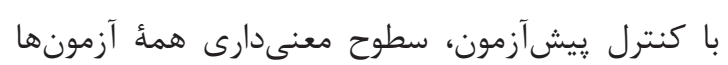

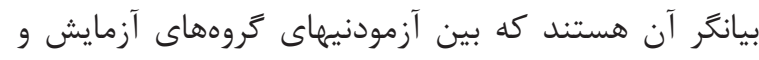

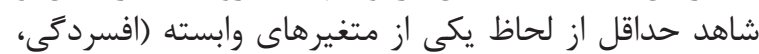

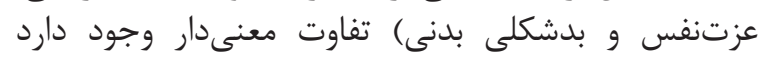
مئابراين فرضئ اول تأييد ميشود.

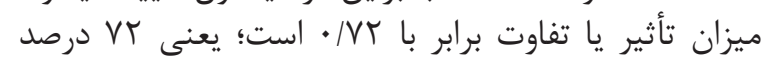

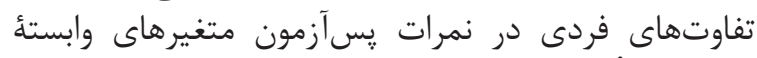

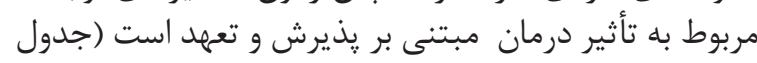

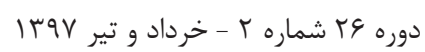

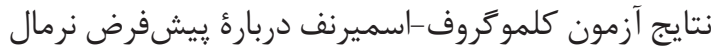

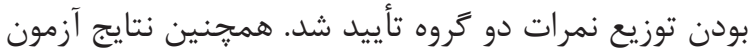

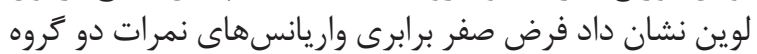

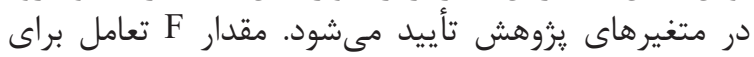

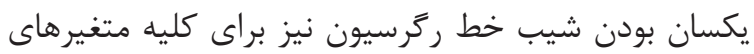

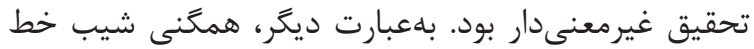

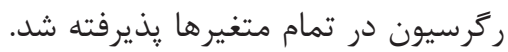

$$
\text { مجله علمى دانشكده يرستارى و مامايى همدان }
$$




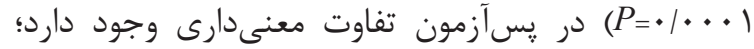

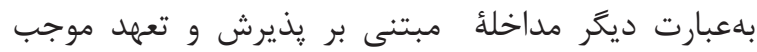

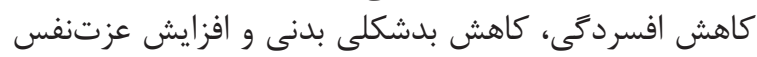

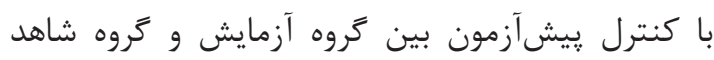

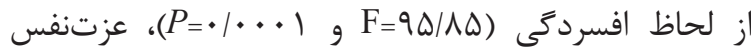

جدول ه. نتايج تحليل كواريانس يكراهه (انكوا) مقايسةُ نمرات يسآزمون افسردىى كروههاى آزمايش و شاهد با كنترل يِيشآزمون

\begin{tabular}{|c|c|c|c|c|c|c|c|c|}
\hline مجذور اتا & توان & معنى دارى Pطح & $\mathbf{F}$ & ميانَين & آزادى & مجموع مربعات & تغييرات & \\
\hline$\cdot 11 \cdot 9$ & $\cdot / \Lambda$. & $\cdot 1 \cdot \cdots 1$ & $9 \Delta / \wedge \Delta$ & $|\cdot r / K r|$ & 1 & | & ييشآزمون & \multirow{3}{*}{ افسردحى } \\
\hline \multirow[t]{2}{*}{$\cdot / v \cdot \Lambda$} & $\cdot / V \Delta$ & $\cdot 1 \cdot \cdots 1$ & $\Delta \Delta / \wedge \varphi$ & $9 \cdot 1109$ & 1 & $9 \cdot 1109$ & تروه & \\
\hline & & & & $1 / \cdot v$ & r & TF/VG & خطا & \\
\hline$\cdot / \vee 99$ & - /VqT & $\cdot \mid \cdot \cdot 1$ & $91 / 90$ & $\Delta F N / A \Lambda$ & 1 & $\Delta F N / A \Lambda$ & يِشآزمون & \multirow{3}{*}{ عزتنفس } \\
\hline \multirow[t]{2}{*}{. /AVr } & - /ATD & $\cdot 1 \cdot \cdots 1$ & $10 V / 99$ & $949 / 11 r$ & 1 & $949 / 11 \%$ & 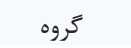 & \\
\hline & & & & $\Delta / 9 \wedge \Lambda$ & r & IrV/Vrr & خطا & \\
\hline - ANG & $\cdot|\Lambda|$ & $\cdot 1 \cdot \cdots 1$ & $11 \mathrm{~V} / \cdot \mathrm{F}$ & $\Lambda \cdot V / 9 \cdot \Delta$ & 1 & $\Lambda \cdot V / G \cdot \Delta$ & يِشآزمون & \multirow{3}{*}{ بدشكلى بدنى } \\
\hline \multirow[t]{2}{*}{$\cdot 11999$} & $\cdot / A T \Delta$ & $\cdot 1 \cdot \cdots \cdot 1$ & $\mid Q T / G$. & $1 \cdot \Delta T / 9 V V$ & 1 & $1 \cdot \Delta r / 9 V V$ & كروه & \\
\hline & & & & 9/9. & rr & $I D N / V \cdot r$ & خطا & \\
\hline
\end{tabular}

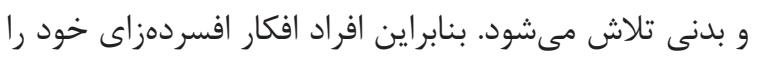

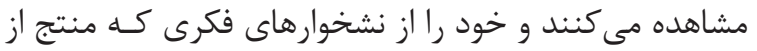

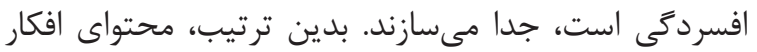

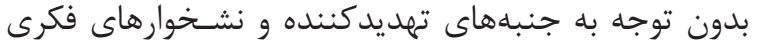

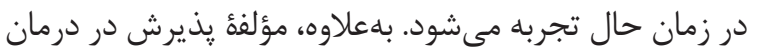

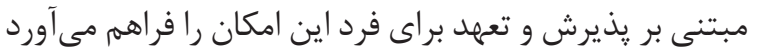

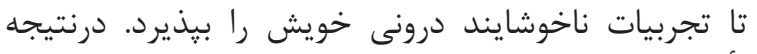

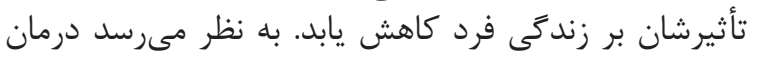

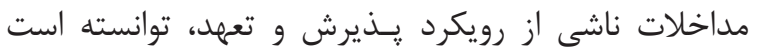

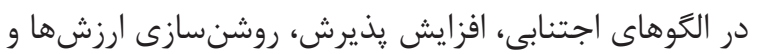

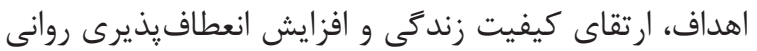

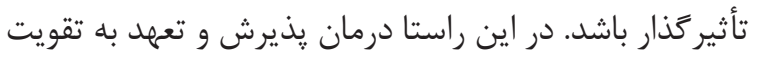

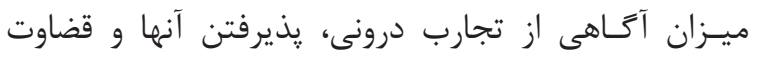

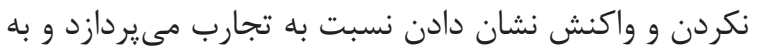

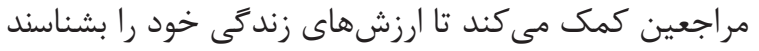

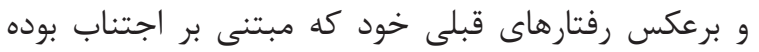

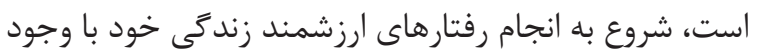

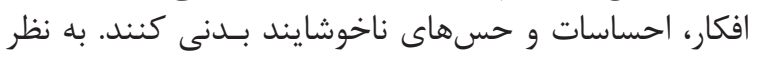

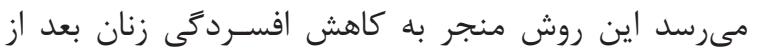

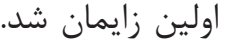

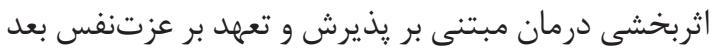

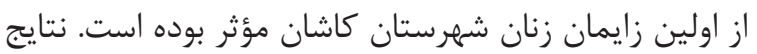

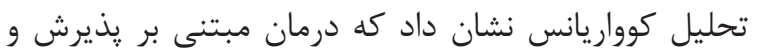

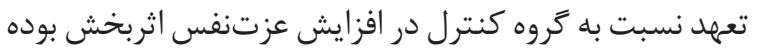

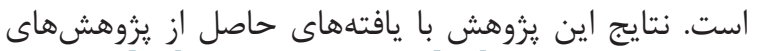

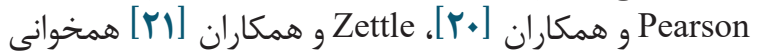

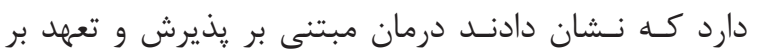
افزايش عزتنفس مؤثر بوده است.

در تبيين اين فرضيه مىتوان كفت كه علت كاهش علائم

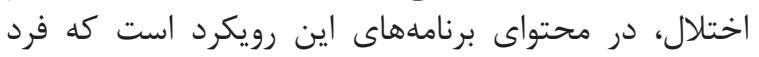

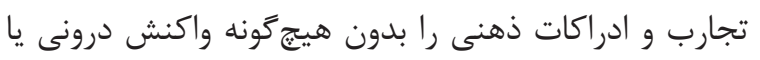

دوره צY شماره Y - خرداد و تير Vq I
آزمودنىهاى گروه آزمايش شده است (جدول ه).

\section{بحث}

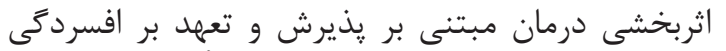

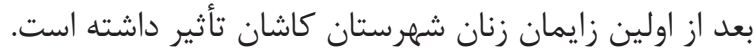

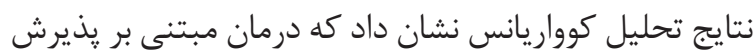

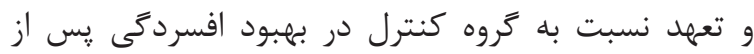

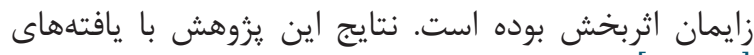

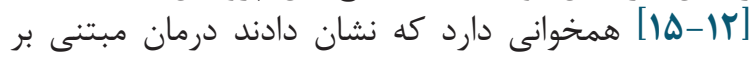
يذيرش و تعهد بر بهبود افسردحى يس إز زائ زايمان مؤثر بوده

در تبيين اين يافتهها مىتوان كفت حون يذيرش و تعهد،

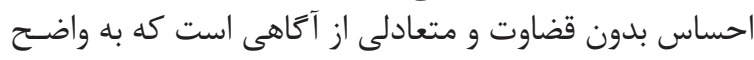

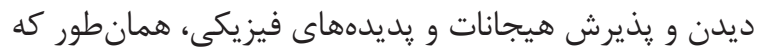

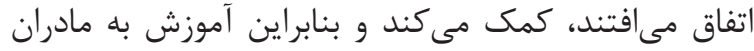

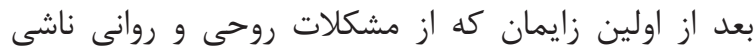

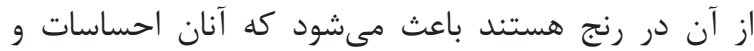

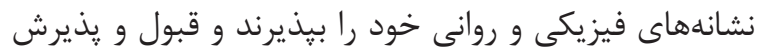

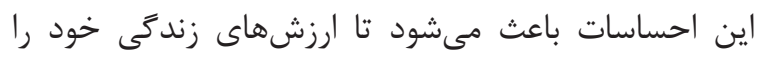

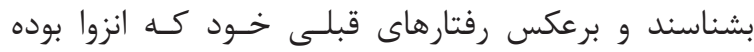

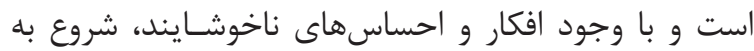

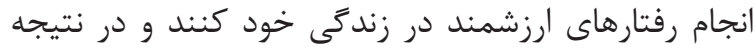

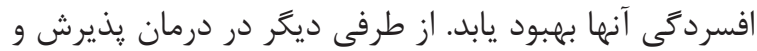

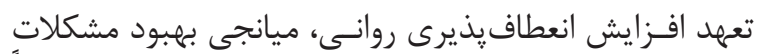

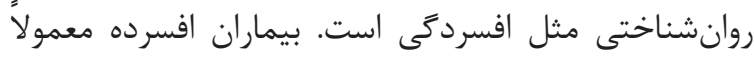

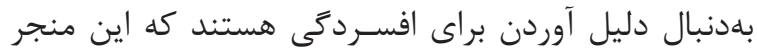

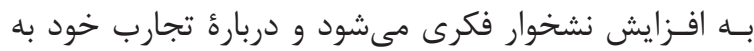

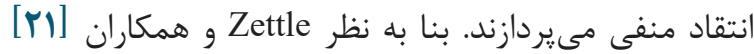

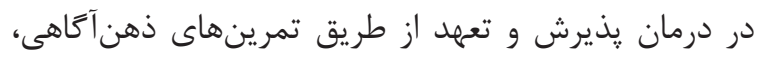

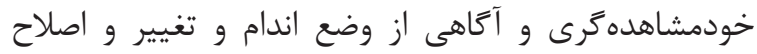

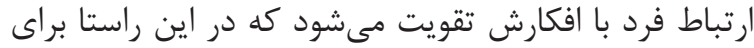

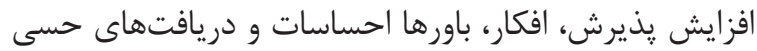

$$
\text { مجله علمى دانشكده يرستارى و مامايى همدان }
$$




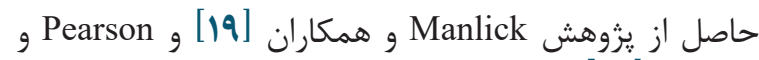

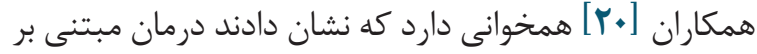

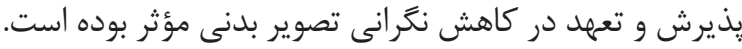
در خصوص تبيين اين فرضيه مىتوان كَفت افراد دجار

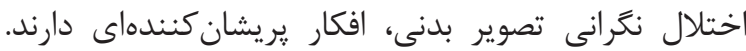

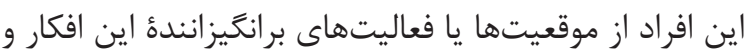

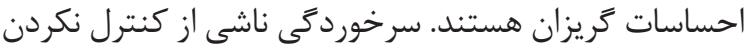

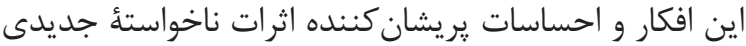

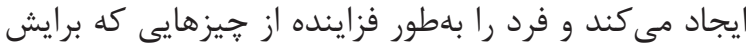

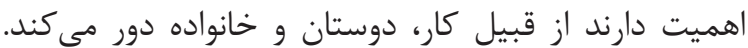

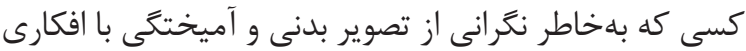

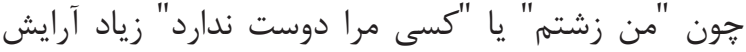

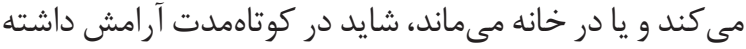

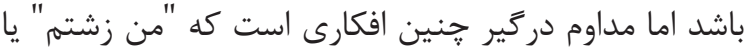

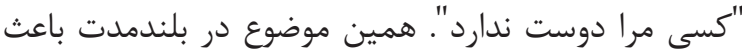

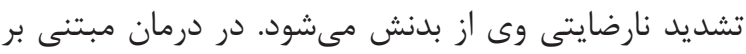

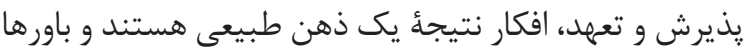

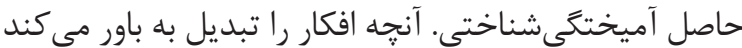

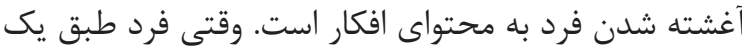

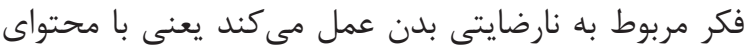

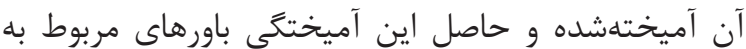

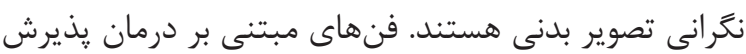

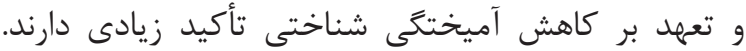

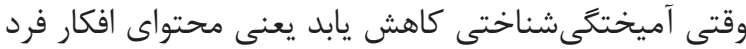

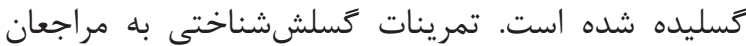

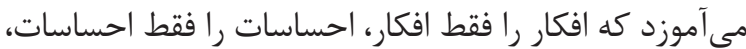

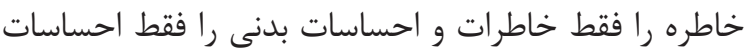

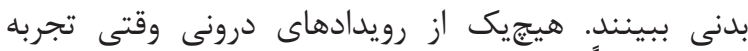

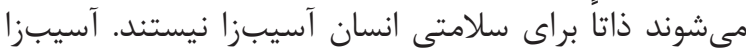

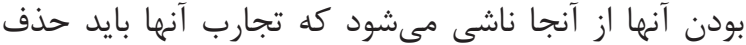

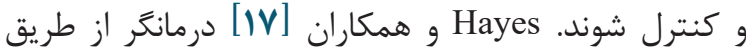

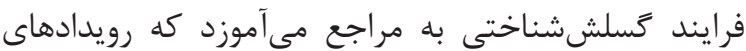

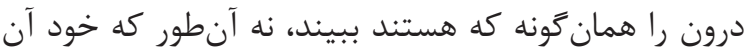

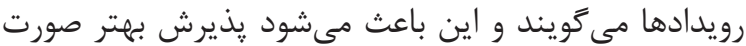

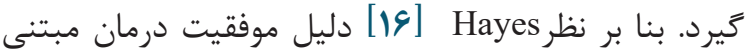

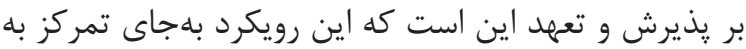

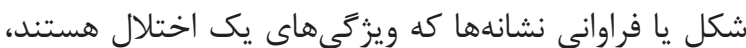

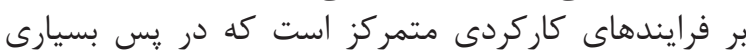

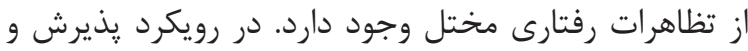

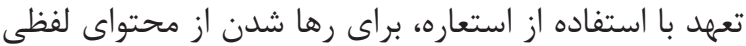

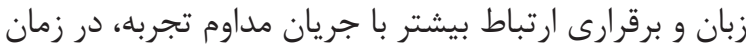

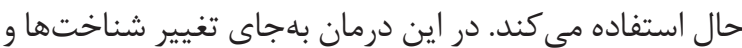

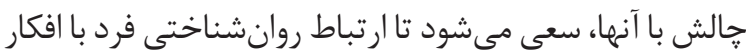

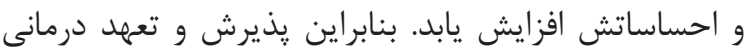

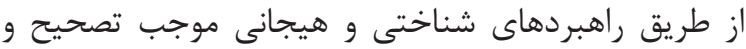

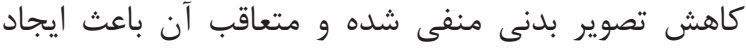

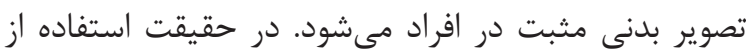

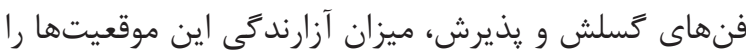

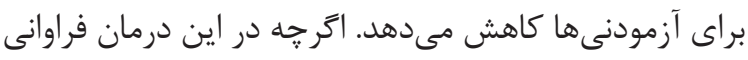

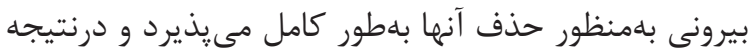

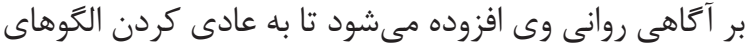

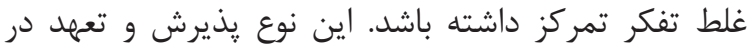

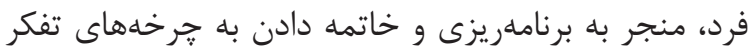

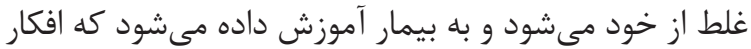

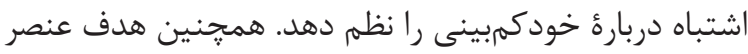

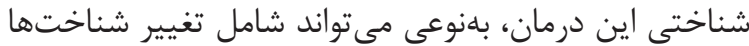

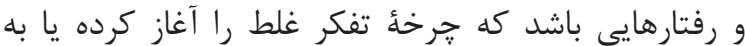

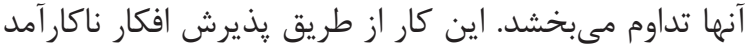

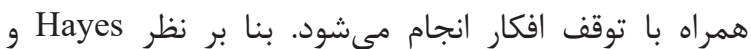

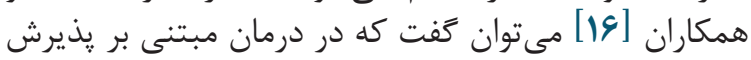

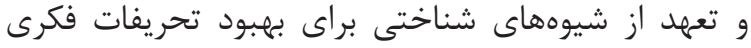

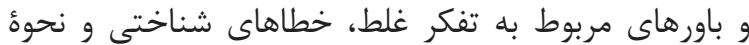

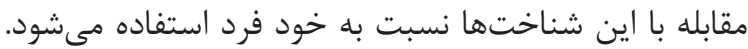

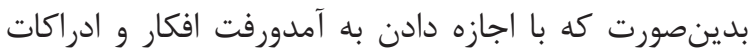

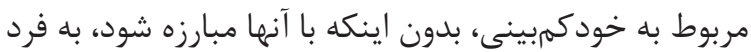

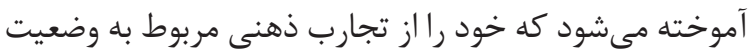

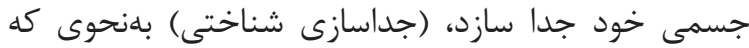

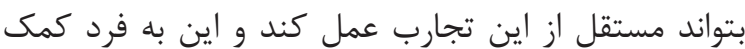

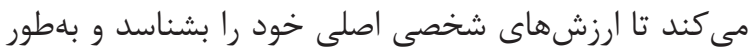

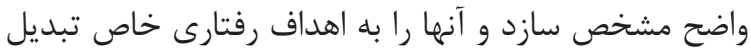

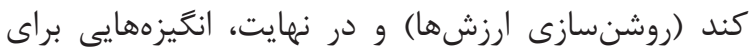

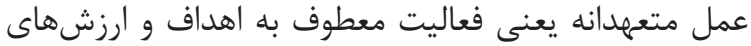

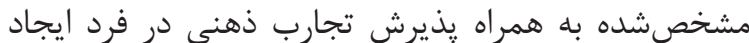

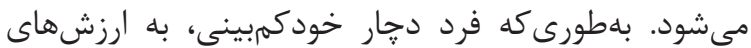

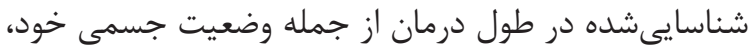

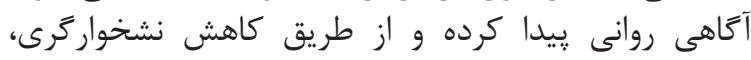

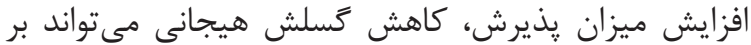

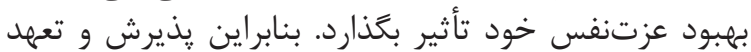

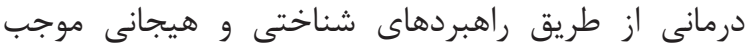
افزايش عزتنفس شده و متعاقب آن باعث ايجادي إنى تفكر مثبت موجبت

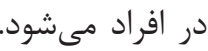

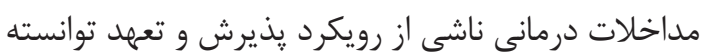

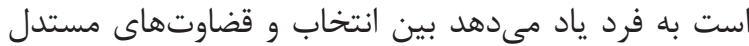

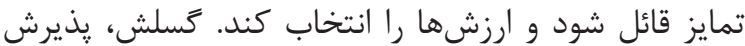

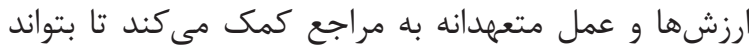

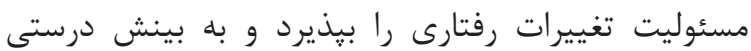

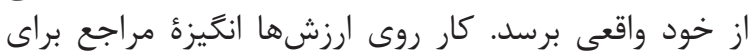

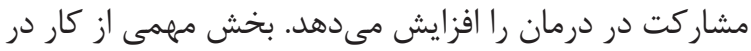

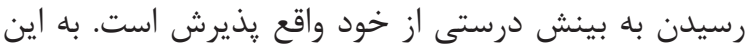

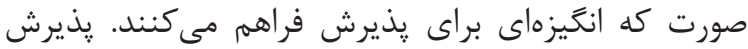

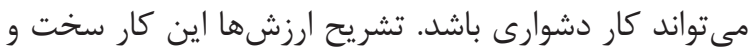

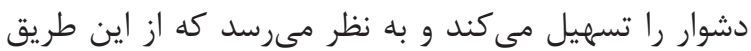

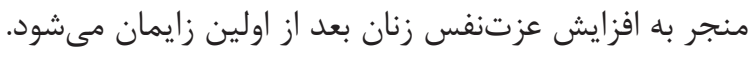
اثربخشى درمان مبتنى بر زيذيرش و تعهلد بر نكرانى تصوير

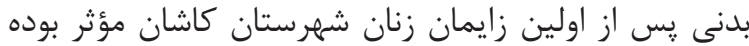

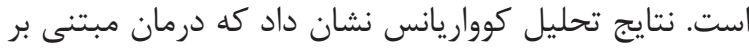

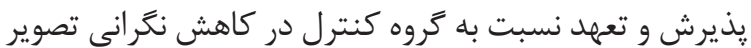

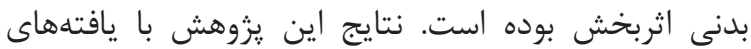


درمان مبتنى بر يذيرش و تعهد در مراكز بهداشتى از ديكر

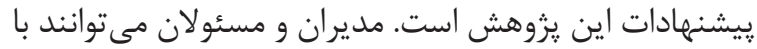

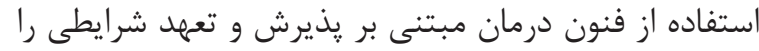

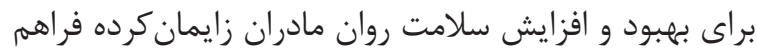

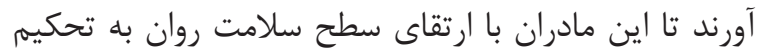

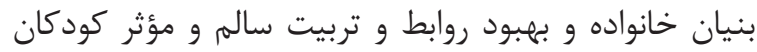

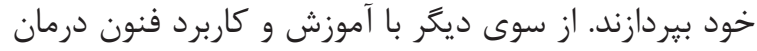

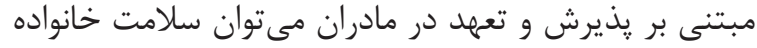

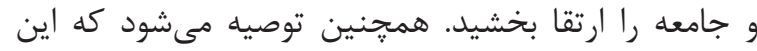

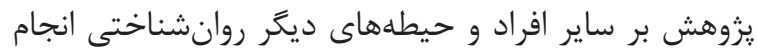

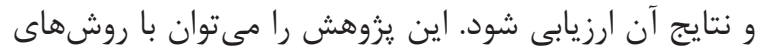

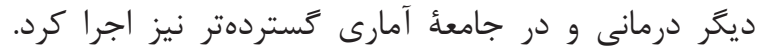

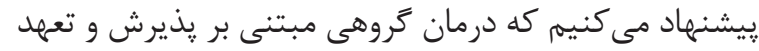

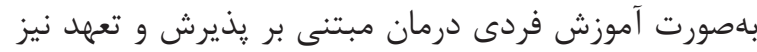

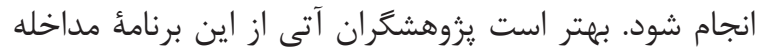

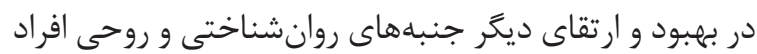

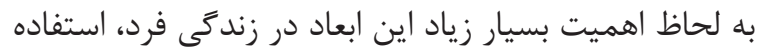

\section{نتيجهل}

يروهش حاضر نشان مى دهد روش درمانى مبتنى بر ريذيرش

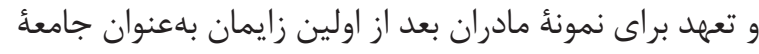

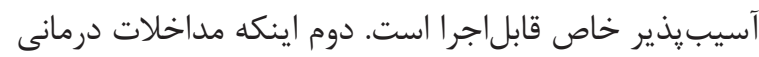

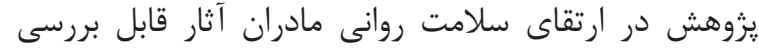

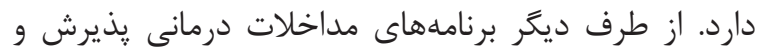

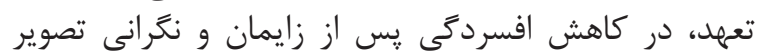

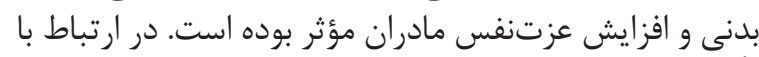

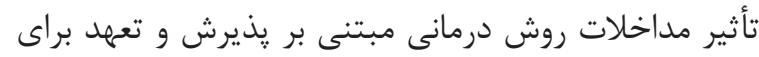

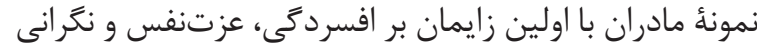

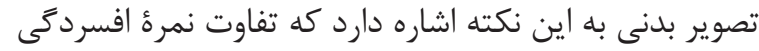

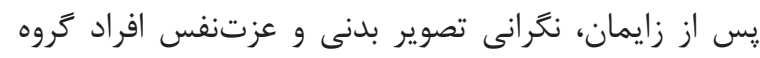

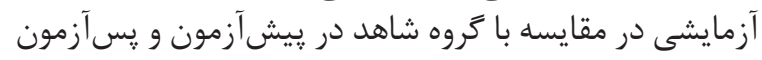
معنادار باقى مانده است.

\section{سياسگزارى}

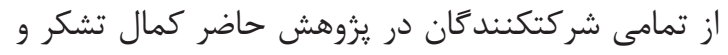

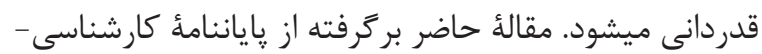

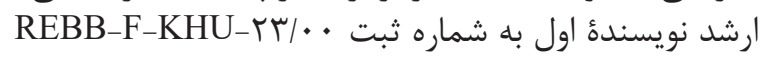

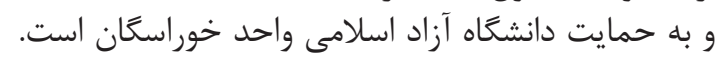

\section{تعارض در منافع} هيجَّونه تضاد منافعى وجود ندارد.

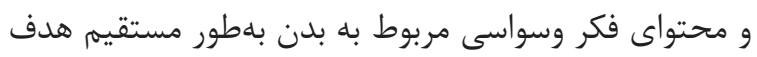

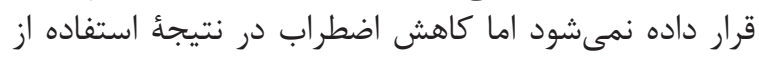

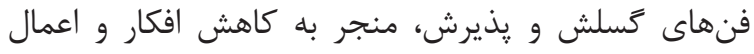

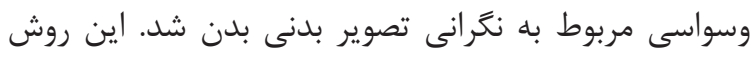

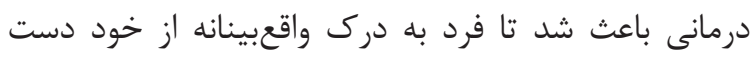

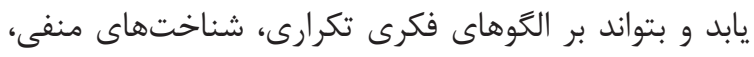

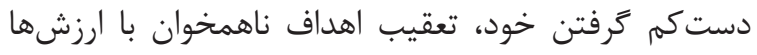

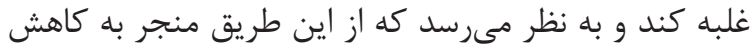

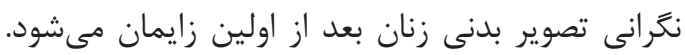

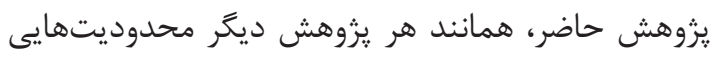

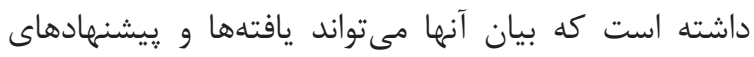

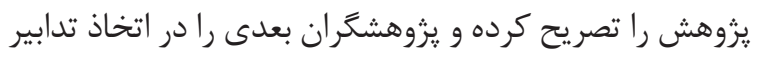

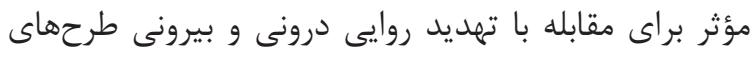

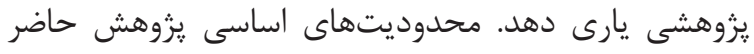

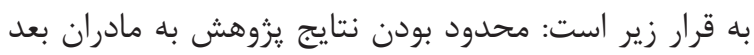

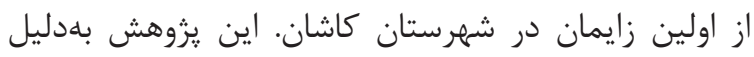

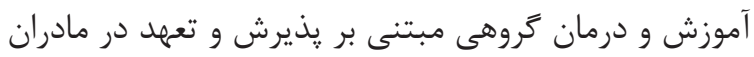

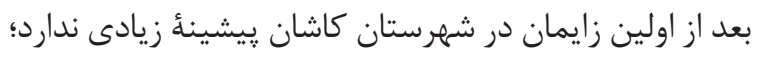

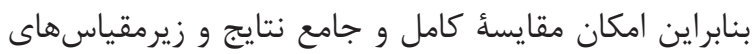

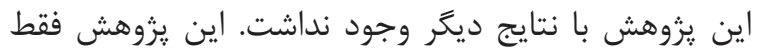

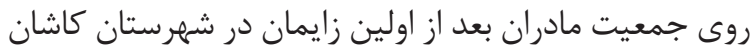

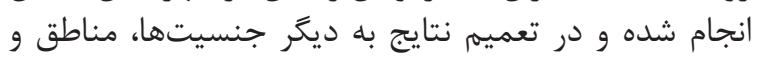

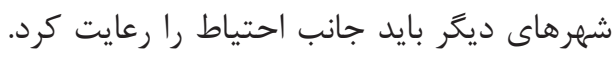

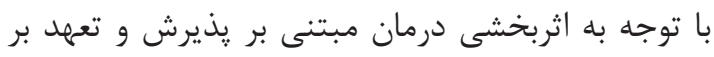

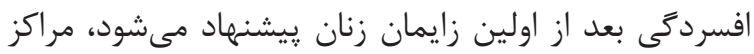

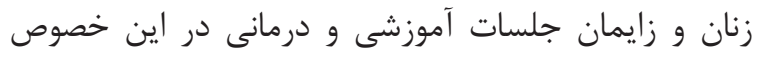

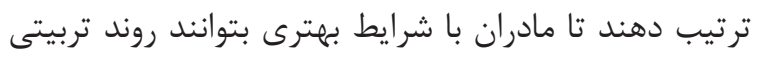

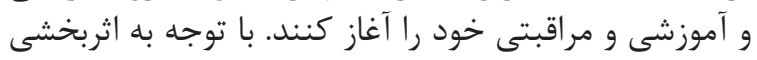

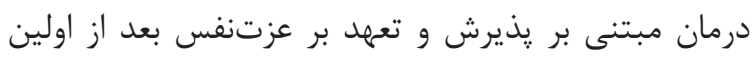

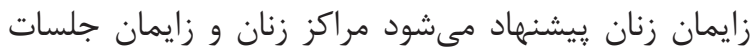

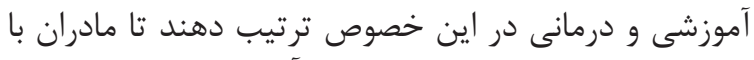
شرايط بهترى بتوانند روند تربيتى و آموزشى و مر مراقبتى خدانى خود را آغاز كنند.

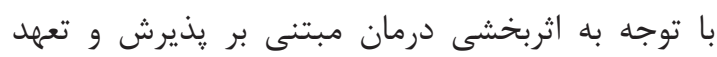

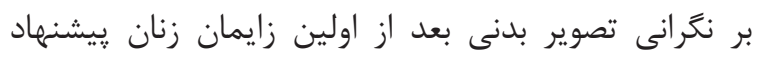

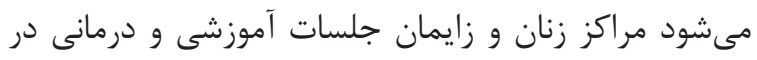

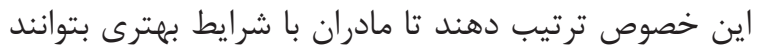

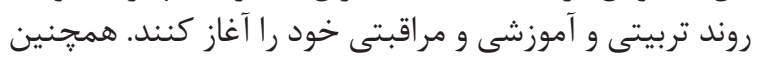

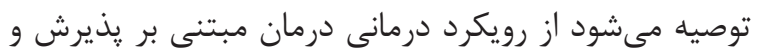

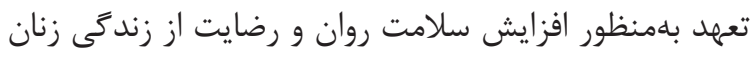
بعد از زايمان استفاده شود. كنجاندن آموزش و كارئ راربرد فنون زنان 


\section{References}

1. Sadock BJ, Sadock VA. Kaplan and Sadock's synopsis of psychiatry: Behavioral sciences/ clinical psychiatry. Philadelphia: Lippincott Williams \& Wilkins; 2011.

2. Gilbert P. Depression: The evolution of powerlessness. New York: Taylor \& Francis; 2016.

3. Rock PL, Roiser JP, Riedel WJ, Blackwell AD. Cognitive impairment in depression: a systematic review and meta-analysis. Psychol Med. 2014;44(10):2029-40. https://doi.org/10.1017/ S0033291713002535 PMID:24168753

4. Torkan H, Blackwell SE, Holmes EA, Kalantari M, Neshat-Doost HT, Maroufi M, et al. Positive imagery cognitive bias modification in treatment-seeking patients with major depression in Iran: A pilot study. Cognit Ther Res. 2014;38(2):132-45. https://doi.org/10.1007/ s10608-014-9598-8 PMID:24634554 PMCID:PMC3951961

5. Ahmadiafshar A, Ghoreishi A, Ardakani SA, Khoshnevisasl P, Faghihzadeh S, Nickmehr P. The High Prevalence of Depression Among Adolescents With Asthma in Iran. Psychosom Med. 2016;78(1):113-4. https://doi.org/10.1097/ PSY.0000000000000286 PMID:26705070

6. Momeni M, Ghorban K, Dadmanesh M, Khodadadi H, Bidaki R, Kazemi Arababadi M, Kennedy D. ASC provides a potential link between depression and inflammatory disorders: A clinical study of depressed Iranian medical students. Nord J Psychiatry. 2016;70(4):280-4. https://doi.org/10.3109/08039488.2015.1100328 PMID:26750863

7. Goshtasebi A, Alizadeh M, Gandevani SB. Association between maternal anaemia and postpartum depression in an urban sample of pregnant women in Iran. J Health Popul Nutr. 2013;31(3):398402. https://doi.org/10.3329/jhpn.v31i3.16832 PMID:24288954 PMCID:PMC3805890

8. Perales M, Cordero Y, Vargas M, Lucia A, Barakat R. Exercise and depression in overweight and obese pregnant women: a randomised controlled trial. Arch Med Deporte. 2015;32(3):70-7.

9. Bohlmeijer ET, Fledderus M, Rokx TA, Pieterse ME. Efficacy of an early intervention based on acceptance and commitment therapy for adults with depressive symptomatology: Evaluation in a randomized controlled trial. Behav Res Ther. 2011;49(1):62-7. https://doi.org/10.1016/j. brat.2010.10.003 PMID:21074752

10. Cash TF, Fleming EC. The impact of body image experiences: development of the body image quality of life inventory. Int $\mathrm{J}$ Eat Disord. 2002;31(4):455-60. https://doi.org/10.1002/ eat.10033 PMID:11948650
11. Orth U, Robins RW. The development of self-esteem. Curr Dir Psychol Sci. 2014;23(5):381-7. https://doi.org/10.1177/0963721414547414

12. Dalrymple KL, Herbert JD. Acceptance and commitment therapy for generalized social anxiety disorder:Apilotstudy. Behav Modif. 2007;31(5):54368. https://doi.org/10.1177/0145445507302037 PMID:17699117

13. Forman EM, Butryn ML, Hoffman KL, Herbert JD. An open trial of an acceptance-based behavioral intervention for weight loss. Cognitive and Behavioral Practice. 2009;16(2):223-35. https:// doi.org/10.1016/j.cbpra.2008.09.005

14. Folke F, Parling T, Melin L. Acceptance and commitment therapy for depression: A preliminary randomized clinical trial for unemployed on long-term sick leave. Cognitive and Behavioral Practice. 2012;19(4):583-94. https://doi. org/10.1016/j.cbpra.2012.01.002

15. Forman EM, Butryn ML, Hoffman KL, Herbert JD. An open trial of an acceptance-based behavioral intervention for weight loss. Cognitive and Behavioral practice. 2009;16(2):223-35. https:// doi.org/10.1016/j.cbpra.2008.09.005

16. Hayes SC, Luoma JB, Bond FW, Masuda A, Lillis J. Acceptance and commitment therapy: Model, processes and outcomes. Behav Res Ther. 2006;44(1):1-25. https://doi.org/10.1016/j. brat.2005.06.006 PMID:16300724

17. Hayes SC, Strosahl KD, Wilson KG. Acceptance and commitment therapy: The process and practice of mindful change. New York: Guilford Press; 2011.

18. Hayes SC, Strosahl KD. A practical guide to acceptance and commitment therapy. Berlin: Springer Science \& Business Media; 2004. https://doi.org/10.1007/978-0-387-23369-7

19. Manlick CF, Cochran SV, Koon J. Acceptance and commitment therapy for eating disorders: Rationale and literature review. J Contemp Psychother. 2013;43(2):115-22. https://doi.org/10.1007/ s10879-012-9223-7

20. Pearson AN, Follette VM, Hayes SC. A pilot study of acceptance and commitment therapy as a workshop intervention for body dissatisfaction and disordered eating attitudes. Cognitive and Behavioral Practice. 2012;19(1):181-97. https:// doi.org/10.1016/j.cbpra.2011.03.001

21. Zettle RD, Rains JC, Hayes SC. Processes of change in acceptance and commitment therapy and cognitive therapy for depression: A mediation reanalysis of Zettle and Rains. Behav Modif. 2011;35(3):265-83. https://doi.org/10.1177/0145445511398344 


\section{PMID:21362745}

22. Hayes SC. Acceptance and commitment therapy, relational frame theory, and the third wave of behavioral and cognitive therapies. Behav Ther. 2004;35(4):639-65. https://doi.org/10.1016/ S0005-7894(04)80013-3 PMID:27993338

23. Bergink V, Kooistra L, Lambregtse-van den Berg MP, Wijnen $\mathrm{H}$, Bunevicius $\mathrm{R}$, van Baar A, Pop V. Validation of the Edinburgh Depression Scale during pregnancy. J Psychosom Res. 2011;70(4):385-9. https://doi.org/10.1016/j. jpsychores.2010.07.008 PMID:21414460

24. Matthey S, Henshaw C, Elliott S, Barnett B. Variability in use of cut-off scores and formats on the Edinburgh Postnatal Depression Scaleimplications for clinical and research practice. Arch Womens Ment Health. 2006;9(6):30915. https://doi.org/10.1007/s00737-006-0152-x PMID: 17013761

25. Bunevicius A, Kusminskas L, Pop VJ, Pedersen CA, Bunevicius R. Screening for antenatal depression with the Edinburgh Depression Scale. J Psychosom Obstet Gynaecol. 2009;30(4):23843. https://doi.org/10.3109/01674820903230708
PMID:19845492

26. Myers JE, Willse JT, Villalba JA. Promoting selfesteem in adolescents: the influence of wellness factors. J Couns Dev. 2011;89(1):28-36. https:// doi.org/10.1002/j.1556-6678.2011.tb00058.x

27. Hills PR, Francis LJ, Jennings P. The school shortform Coopersmith self-esteem inventory: Revised and improved. Can J Sch Psychol. 2011;26(1):6271.https://doi.org/10.1177/0829573510397127

28. Ünal S. Evaluating the effect of self-awareness and communication techniques on nurses' assertiveness and self-esteem. Contemp Nurse. 2012;43(1):90-8. https://doi.org/10.5172/ conu.2012.43.1.90 PMID:23343237

29. Littleton HL, Axsom D, Pury CL. Development of the body image concern inventory. Behav Res Ther. 2005;43(2):229-41. https://doi. org/10.1016/j.brat.2003.12.006 PMID:15629752

30. Grabe S, Ward LM, Hyde JS. The role of the media in body image concerns among women: a meta-analysis of experimental and correlational studies. Psychol Bull. 2008;134(3):460. https://doi.org/10.1037/0033-2909.134.3.460 PMID:18444705 